\title{
IMPLEMENTASI KEBIJAKAN PERATURAN BANK INDONESIA NO.8/4/PBI/2006 SELF ASSESSMENT GOOD CORPORATE GOVERNANCE PADA BANK GO PUBLIC
}

\author{
Mujiburrahman Thontowi ${ }^{1}$, Sri Rejeki Hartono ${ }^{2}$
}

\begin{abstract}
Abstrak
Penelitian tentang implementasi Good Corporate Governance (GCG) berdasarkan Peraturan Bank Indonesai (PBI) No 8/4/PBI/2006 tentang pelaksanaan GCG bagi Bank Umum mengankat tiga permasalahan. Pertama, pengaturan selfassessment GCG bagi bank umum berdasarkan PBI. Kedua, kendala dalam melakukan self assessment GCG.Ketiga, pemikiran upaya untuk mengatasi kendala dalam melakukan self assessment GCG. Penelitian ini menggunakan metode yuridis empiris. Pengumpulan data sekunder dalam penelitian ini dilakukan dengan studi pustaka dan studi dokumentasi.analisa data menggunakan analisa data kualitatif. Hasil penelitian mengungkapkan bahwa semua bank harus menjalankan kegiatanusaha sesuai dengan prinsip prinsip yang terkandung dalam peraturan bank Indonesia. Implementasi GCG diperlukan agar perusahaan Perbankan dikelola secara amanah, efisien, professional dan tidak merugikan kepentingan stakeholders. Self assessment GCG mendorong tegaknya prinsip transparancy, accountability, responsibility, independence dan fairness. Kendala yang dihadapi oleh perusahaan perbankan saat melaksanakan selff assessment GCG bersifat internal dan external.
\end{abstract}

Kata kunci:Peraturan Bank Indonesia, Good Corporate Governance, Go Public

\footnotetext{
${ }^{1}$ Mahasiswa Program Studi Magister IImu Hukum UNDIP

${ }^{2}$ Dosen Program Studi Magister IImu Hukum UNDIP
} 


\begin{abstract}
Research on the implementation of Good Corporate Governance (GCG) based on the Indonesia Bank Regulation (PBI) No. 8/4 / PBI / 2006 regarding the implementation of GCG for Commercial Banks pick-three problems. First, the setting selfassessment GCG for commercial banks by PBI. Second, difficulties in implementing the GCG self assessment. Third, thinking efforts to overcome difficulties in implementing GCG self assessment. This study uses empirical jurisdiction. Secondary data collection in this study conducted by literature study and documentation study. analysis of data using qualitative data analysis. Results of the study revealed that all banks have to conduct business in accordance with the principles contained in the Bank Indonesia regulations. GCG implementation necessary for companies Banking managed trustworthy, efficient, professional and does not harm the interests of stakeholders. GCG self assessment encourages upholding principles of Transparency, accountability, responsibility, independence and fairness. Constraints faced by the banking company is currently carrying out selff GCG assessment is internal and external.
\end{abstract}

Keywords: Bank Indonesia Regulation, GCG, Go Public 


\section{A. PENDAHULUAN}

\section{Latar Belakang}

$\begin{array}{llr}\text { Peraturan di } & \text { bidang } \\ \text { perbankan telah } & \text { membawa }\end{array}$
kemanfaatan kepada masyarakat ke arah lebih terbuka. Keterbukaan akan memberikan dampak yang positif dengan tersedianya informasi yang akurat sebagai dasar untuk membuat keputusan mengenai berbagai macam aspek dalam perusahaan. Keterbukaan akan menciptakan profesionalitas dalam pengelolaan perusahaan kearah yang lebih jujur dan meningkatkan sistem pengawasan administrasi perusahaan.

Bank Indonesia dalam mengawasi bank tidak lepas dari peran bank sentral sebagai Prudent Supervisor. Pengertian Prudent Supervisor adalah prinsip pengasawan dengan hati hati dalam pengelolaan perbankan $^{3}$. Tugas bank sentral adalah menciptakan regulasi yang sesuai dengan kebutuhan industri perbankan. Regulasi mewajibkan bank bertanggungjawab secara

\footnotetext{
${ }^{3}$ Ferry Idroes, Manajemen Risiko Perbankan, Pemahaman Pendekatan 3 Pilar Kesepakatan Basel II, Terkait Implementasi Regulasi dan Pelaksanaannya di Indonesia, Rajawali Press, 2008, hal 26
}

proposional atas setiap risiko dari aktivitas yang diambil.

GCG merupakan salah satu instrument untuk memperkuat kondisi internal perbankan nasional. Oleh karena itu GCG adalah prasayarat untuk sustainabilitas bank $^{4}$. Upaya untuk meningkatan mutu manajemen dan operasi Bank dengan memperkuat GCG, pada tahun 2004 sampai dengan tahun 2006, BI menyusun Peraturan Bank Indonesia (PBI) tentang GCG sebagai salah satu bentuk standard minimum pelaksanaan GCG bagi Bank Umum. Pada tanggal 30 Januari 2006 Gubenur BI menetapkan PBI Nomor 8/4/PBI/2006 tentang pelaksanaan GCG bagi bank umum.

GCG di sektor perbankan cukup penting maka dibutuhkan penelitian yang komprehensif tentang pelaksanaan self assessment GCG bagi bank umum. Kajian ini penting dilakukan mengingat kewajiban dari BI untuk

\footnotetext{
${ }^{4}$ Binhadi, Elaboration of Indonesian Code of Corporate Governance, Sustaining Value though GCG based on business practices" National Committee on Governance, Nusa Dua, Bali, 31 August 2007
} 
melaksanakan self assessment. Dari penelitian diharapakan memberi gambaran pelaksanaan self assessment berdasarkan peraturan BI. Pusat perhatian dalam
penelitian ini adalah tentang
implementasi GCG berdasarkan Peraturan Bank Indonesai No 8/4/PBI/2006 tentang pelaksanaan GCG bagi Bank Umum. Pada saat tesis ini ditulis bank sudah enam kali menerbitkan laporan pelaksanaan GCG yaitu pada tahun 2007, 2008, 2009, 2010, 2011 dan 2012. Berdasarkan latar belakang diatas maka dalam penelitian ini penulis mengambil judul "Implementasi Kebijakan Peraturan Bank Indonesia No 8/4/PBI/2006 Self Assessment Good Corporate Governance bagi bank Go Public".

\section{Permasalahan}

Berdasarkan uraian latar belakang tersebut, maka dapat dirumuskan permasalahan sebagai berikut:

1. Bagaimana implementasi kebijakan Peraturan Bank Indonesia No 8/4/PBI/2006 self assessment GCG bagi bank go public?
2. Kendala apakah yang dihadapi oleh bank go public dalam melakukan self assessment GCG?

3. Bagaimana upaya upaya untuk mengatasi kendala melaksanaan self assessment GCG di bank go public?

\section{Tinjauan Pustaka}

Latarbelakang GCG mulai pertama kali pada tahun 1970an setelah terungkap sejumlah skandal korporasi di Amerika Serikat ketika beberapa perusahaan diketahui terlibat dalam kegiatan berpolitik yang tidak sehat dan dilanda korupsi ${ }^{5}$ Kemudian terjadi kegagalan pada perusahaan perusahaan berskala besar baik di sektor keuangan maupun bukan keuangan ${ }^{6}$, berikut skandal skandal keuangan dan krisis ekonomi di berbagai negara, banyak perusahaan memberi perhatian khusus pada pentingnya penataan GCG.

\footnotetext{
${ }^{5}$ Syakhroza, Corporate Governance: Sejarah dan Perkembangan. Teori, Model dan System Governance serta aplikasinya pada perusahaan BUMN. Jakarta: lembaga penerbit FEIU, Jakarta, 2005, hal 3 ${ }^{6}$ Sutojo dan Aldridge, Good Corporate Governance: Tata Kelola Perusahaan yang sehat, Jakarta: Dharma Mulia Pustaka, 2005, hal 1
} 
Respons terhadap isu GCG bertambah meningkat lagi setelah lembaga lembaga keuangan internatonal seperti World Bank dan Asian Development Bank menyatakan bahwa penyebab krisis keuangan yang melanda berbagai Negara, terutama asia, pada tahun 1997 tidak lain adalah buruknya praktik pelaksanaan $\mathrm{GCG}^{7}$.

\section{a. Pengertian Good Coporate}

\section{Governance}

Pemikiran mengenai corporate Governance menurut catatan para ahli, khusunya para ahli ekonomi dan ahli hukum, telah memiliki sejarah yang panjang. Walau demikidan, penyebutan GCG sebagai konsep yang baku dan mendapat respons yang luas belum berlangsung lama yaitu kurang dari dua dasawarsa ${ }^{8}$.

Istilah Tata kelola perusahaan atau dikenal dengan good corapoate governance menjadi isu penting

\footnotetext{
${ }^{7}$ Iqbal dan Mirakhor, Pengantar Keuangan Islam: Teori dan Praktik. Diterjemahkan oleh AK Anwar. Kencana , Jakarta, 2008, hal 343. ${ }^{8}$ Mal An Abdullah, Corporate Governance Perbankan Syariah di Indonesia, Ar Ruzz Media, Yogyakarta, 2010, hal 23
}

dalam tahun 1990-an ${ }^{9}$. Wancana mengenai corporate governance telah berkembang sampai saat ini sejak krisis ekonomi yang melanda negara negara di Asia terutama di Indonesia $^{10}$. Namun konsep Corporate Governance ${ }^{11}$ dikenal telah sejak lama di negara negara maju (Eropa dan Amerika) dengan adanya konsep pemisahan antara kepemilikan pemilik modal dengan para manajemen dalam perusahaan.

Istilah corporate governance pertama kali diperkenalkan oleh Cadbury Committee tahun 1992 dikenal sebagai Cadburry Report. Laporan ini dipandang sebagai titak balik yang menentukan praktik corporate governance di seluruh dunia $^{12}$.

\footnotetext{
${ }^{9}$ Rianto Nugroho, Reinventing

Pembangunan: Menata Ulang Pebangunan untuk Membangun Indonesia Baru dengan Keunggulan Blobal, PT Elek Media Komputindo, Jakarta, 2003, hlm 114 ${ }^{10} \mathrm{G}$. Supriyitno, dkk, Komiten Menegakkan Good Coprate governance, the Indonesian Institute for Corporate Governance, Jakarta, 2004, hlm 14

${ }^{11}$ Siddharta Uta, ma dan Cynthia Afriani, Praktik Coporate Goverannce dan Penciptaan Nilai Perusahaan: Studi Empiris di BEJ, Usahawan No 08 TH XXXIV/Agustus 2005, Jakarta, hlm 3

${ }^{12}$ I. Nyoman Tjager dkk, Coporate Governance Tantangan dan kesempatan bagi komunitas bisnis Indonesia, PT Prenhalindo, Jakarta, 2003, hIm 24
} 
Dalam publikasinya mengengenai prinsip pirnsip GCG, OECD menjelaskan bahwa GCG mencakup serangkaian tata hubungan antara manajemen perusahaan, dewan pengurus, pemegang saham dan stakeholders lainnya. GCG juga menyediakan struktur untuk menyususn tujuan perusahaan, dan menetukan sarana untuk mencapai tujuan tersebut dan pemantauan kinerjanya. GCG juga harus menyediakan insentif yang memadai bagi dewan pengurus dan manajemen untuk memicu tercapaianya tujuan perusahaan sejalan dengan kepentingan perusahaan sendiri dan para pemegang saham, dan harus memudahkan dilakukannya pemantauan yang efektif. Adanya sistem GCG yang efektif di dalam sebuah perusahaan dan dalam perekonomian secara keseluruhan, akan membantu melahirkan tingkat keyakinan tertentu yang diperlukan untuk berfungsi ekonomi pasar secara baik.

$\begin{array}{rcc}\text { Menurut } & \text { The Basel } \\ \text { Committee on Banking, GCG }\end{array}$ mencakup metode bagaimana bisnis dan urusan bank dikelola oleh para pengurus dan manajemen senior, yang mempengaruhi bagaimana mereka $^{13}$ :

1. Menyusun tujuan tujuan perusahaan

2. Mengoperasikan bisnis bank sehari hari

3. Memenuhi kewajiban akuntabilitas terhadap para pemegang saham dan mempertimbangkan kepentingan stakeholder lain

4. Mengatur agar aktivitas dan perilaku perusahaan sejalan dengan harapan agar bank beroperasi secara aman dan baik dan sejalan pula dengan ketentuan hukum dan regulasi

5. Melindungi kepentingan para deposan.

Menurut Forum for Corporate Governance in Indonesia (FCGI) GCG adalah seperangkat peraturan peraturan yang

\footnotetext{
${ }^{13}$ Basel Committee on Bankin Supervision, Enhancing Corporate Governance for Banking Organizations: Bassel: Bank for International Settlement Press, 2006 hal 4
} 
menetapkan hubungan antara pemegang saham, pengurus, pihak kreditur, pemerintah, karyawan serta para pemegang kepentingan intern dan ekstern lainnya sehubungan dengan hak hak dan kewajiban mereka, atau dengan kata lain sistem yang mengarahkan dan mengendailkan perusahaan.

\section{b. Prinsp Dasar Good} Corporate Governance

1. Prinsip Transpancy Bank Harus mengunkapakan informasi secara tepat waktu, memadai, jelas akurat dan dapat diperbandingkan serta mudah diakses oleh stakeholders sesuai dengan haknya.

2. Prinsip AccountabiltyBank harus menetapkan tanggungjawab yang jelas dari masing masing organ organisasi yang selaras dengan visi misi sasadran usaha dan strategi perusahaan. Bank harus meyakini bahwa semua organ organisasi bank mempunyai kompetensi sesuai dengan tanggungjawab dan memahami perananya dalam pelaksanaan GCG.

3. Prinsip ResponsibiltyUntuk menjaga kelangsungan usahanya, bank harus berpegang pada prinsip kehati-hatian (prudential banking practices) dan menjamin dilaksankaan ketentuan yang berlaku. Bank harus bertindak sebagai good corporate citizen termasuk peduli terhadap lingkungan dan melaksanakan tanggungjawab sosial.

4. Prinsip IndependencyBank harus menghindari terjadi dominasi yang tidak wajar oleh shareholders manapun dan tidak terpengaruh oleh kepentingan sepihak serta bebas dari benturan kepentingan (Conflict of Interest). Bank dalam mengambil keputusan harus obyektif dan bebas dari segala tekanan dari pihak manapun.

5. Prinsip Kewajaran Bank harus senantiasa mempperhatikan seluruh 
staholders berdasarkan azas kesetaraan dan kewajaran (equal treatment). Bank harus memberikan kesempatan kepada seluruh stakeholders untuk member masukan dan menyapikan pendapat bagi kepentingan bank serta mempunyai akses terhadap informasi seesai dengan prinsip keterbukaan.

\section{Metode Penelitian}

Pendekatan masalah dalam penelitian ini menggunakan metode yuridis empiris karena merupakan penelitian hukum mengenai implementasi ketentuan hukum normatif secara in action yang pada setiap peristiwa hukum tertentu yang terjadi baik dalam masyarakat ${ }^{14}$ maupun dalam industri perbankan yang berhubungan dengan GCG.Metode pengumpulan data sekunder dalam penelitian ini dilakukan dengan studi pustaka dan studi dokumentasi ${ }^{15}$.

\footnotetext{
${ }^{14}$ Abdul Kadir Muhammad, Hukum dan Penelitian Hukum, Bandung, PT Citra Aditya Bakti, 2004 hal 134

${ }^{15}$ Soerjono Soekantoi \& Sri Mamudji, Penelitian Hukum Normatif Suatu Tinjauan Singkat, PT.RajaGrafindo Persada Jakarta 2004hal 13
}

Pengumpulan data primer dilakukan dengan wawancara. Data primer digunakan dalam penelitian hukum ini karena bersifat empiris yaitu dengan field research (studi lapangan).Spesifikasi penelitian berupa deskriptif analitis yaitu suatu peneiltian yang berusaha menggambarkan masalah hukum, sistem hukum dan mengkajinya sesuai dengan kebutuhan dari penelitian. Metode analisa data dalam penelitian ini disebut analisa data kualitatif dan karena merupakan penelitian yuridis empiris.

\section{B. HASIL PENELITIAN DAN PEMBAHASAN}

1. Implementenasi Self Assesment Good Corporate Governance pada bank go public.

Ketentuan GCG telah ditetapkan dalam PBI No 8/4/PBI/2006 tentang pelaksanaan Good Corporate Governance bagi Bank Umum sejak tanggal 30 Januari 2006, namun implementasi penuh baru akan dilaksanakan pada tahun 2007. Berdasarkan Pasal 2 PBI No 8/4/PBI/2006 mewajibkan industri perbankan untuk memenuhi 5 (lima) prinsip dasar yakni keterbukaan 
(transparency), akuntabilitas

(accountability),

pertanggungjawaban (responsibility), independensi (independency), dan kewajaran (fairness) yang sekurang kurangnya meliputi :

1. Pelaksanaan tugas dan tanggung jawab Dewan Komisaris dan Direksi;

2. Kelengkapan dan pelaksanaan tugas komite-komite dan satuan kerja yang menjalankan fungsi pengendalian intern bank;

3. Penerapan fungsi kepatuhan, auditor internal dan auditor eksternal;

4. Penerapan manajemen risiko, termasuk system pengendalian intern;

5. Penyediaan dana kepada pihak terkait dan penyediaan dana besar;
6. Rencana strategis

Bank; dan

7. Transparansi kondisi keuangan dan non keuangan bank

Selain itu,berdasrakan Pasal 61 dan Pasal 65 PBI No 8/4/PBI/2006, bank juga diwajibkan untuk melaksanakan transparansi kepada publik melalui penyusunan laporan pelaksanaan good corporate governance serta melakukan penilaian (self assessment) atas pelaksanaan good corporate governance. Laporan GCG tersebut paling lambat disampaikan oleh bank 5 bulan setelah tahun buku berakhir, dengan demikian, mulai awal bulan Juni 2008 masyarakat dapat melihat laporan GCG bank pada website bank yang bersangkutan ${ }^{16}$.Kepada seluruh bank umum telah diminta untuk melakukan penilaian sendiri (self assesment) atas pelaksanaan GCG dan menyampaikan laporan penilaian tersebut kepada Bank Indonesia untuk dievaluasi.

Pada tahun 2006 Bank Indonesia sebagai langkah persiapan

\footnotetext{
${ }^{16}$ Bank Indonesia, Laporan Pengawasan Perbankan, Jakarta, 2007 hal 5
} 
pelaksanaan self assessment dan melihat kesiapan bank dalam melaksanakan prinsip-prinsip GCG, telah dilaksanakan pre self assessment terhadap bank. Hasil pre self assessment tersebut menunjukkan bahwa $97 \%$ bank telah menerapkan minimal $50 \%$ prinsipprinsip GCG sebagaimana dimaksud dalam ketentuan Bank Indonesia ${ }^{17}$. Berdasarkan evaluasi terhadap hasil self assessment dimaksud mayoritas bank umum telah dapat memenuhi target persiapan pelaksanaan $\mathrm{GCG}^{18}$.

Untuk pertama kalinya pada tahun 2007 seluruh bank diminta untuk menyampaikan laporan pelaksanaan Good Corporate Governance (GCG) yang berisi self assessment pelaksanaan GCG serta aspek-aspek pelaksanaan GCG lainnya. Dengan informasi tersebut, diharapkan masyarakat dapat melakukan pengawasan melalui mekanisme pasar. Masyarakat dapat mengetahui kinerja bank serta pelaksanaan GCG bank sehingga membantu masyarakat menentukan pilihan kepada bank mana mereka

\footnotetext{
${ }^{17}$ Bank Indonesia, Laporan Pengawasan Perbankan, Jakarta, 2006 hal 32

${ }^{18}$ Bank Indonesia, Laporan Pengawasan Perbankan, Jakarta, 2006 hal 44
}

akan mempercayakan penyimpanan dan pengelolaan dananya.

Sejak tahun 2007, Bank Indonesia mulai melakukan evaluasi atas pelaksanaan GCG dengan melakukan pemeriksaan atas 11 Faktor Penilaian Pelaksanaan GCG Laporan pelaksanaan GCG dan pelaporan Internal; (11) Rencana Strategis Bank, dengan klasifikasi nilai peringkat komposit 1 sampai 5 yaitu : sangat baik; baik; cukup baik; kurang baik; dan tidak baik sebagaimana yang tercantum dalam Surat Edaran Bank Indonesia No. 9/12/DPNP perihal pelaksanaan Good Corporate Governance bagi Bank Umum.

Hasil pemeriksaan pelaksanaan GCG dari 2007-2010 digambarkan perkembangan implementasi GCG melalui grafik dibawah ini. Dari Graif tersebut telah menunjukan bahwa terjadi pengingkatan pelaksanaan GCG sejak tahun 2007 sampai dengan 2010.

Adapun profil rating pelaksanaan GCG berdasarkan hasil pemeriksaan awal terhadap seluruh bank umum selama tahun 2007 menunjukkan predikat pelaksanaan 
GCG yang cukup baik, tercermin dari peringkat komposit mayoritas bank yang tergolong cukup baik.

Pada tahun kedua pelaksanaan self assessment implementasi good corporate governance lebih baik, antara lain ditunjukkan dengan meningkatnya jumlah bank yang tergolong Baik, yaitu dari $38,8 \%$ menjadi $44,6 \%$, sedangkan yang tergolong Tidak Baik turun dari 4,3\% menjadi $0,8 \%^{19}$.

Sedangkan hasil self assessment yang dilakukan pada tahun 2009 bagi Bank Umum dalam implementasi Good Corporate Governance (GCG) dengan hasil yang cukup baik. Hasil penilaian pengawasan terhadap implementasi GCG bank umum menunjukkan bank telah menerapkan prinsip prinsip GCG dengan baik, yakni $37,4 \%$ tergolong Baik, dan 55,7\% Cukup Baik dan 2,6\% Sangat Baik $^{20}$.Kualitas implementasi GCG bank umum semakin meningkat seiring dengan semakin besarnya peran dan keberadaan pihak independen dalam melakukan check and balance $e^{21}$.

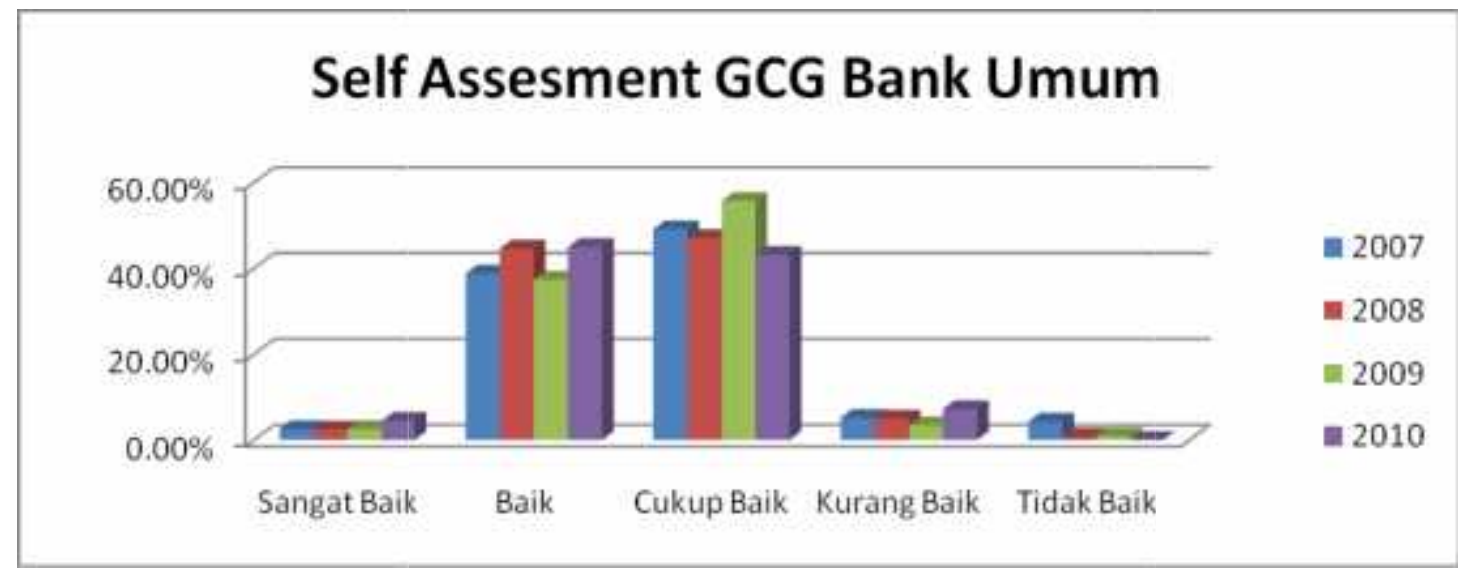

\footnotetext{
${ }^{19}$ Bank Indonesia, Laporan Pengawasan Perbankan 2008 hal 5
}

\footnotetext{
${ }^{20}$ Bank Indonesia, Laporan Pengawasan Perbankan 2009 hal 7

${ }^{21}$ Bank Indonesia, Laporan Pengawasan Perbankan 2009 hal 47
} 
Setelah empat tahun bank bank yang masuh perlu pelaksanaan self assessment GCG di perbaikan yaitu 5 bank mendapatkan Indonesia perbankan menunjukan predikat cukup bank dan 1 bank perkembangan yang posisitif dengan Kurang baik.

di tandai dengan bank dengan predikat sangat baik meningkat dari $2.6 \%$ menjadi 4.5 dan bank dengan predikat baik juga meningkat dari $37.4 \%$ menjadi $45.0 \%$. Selain itu Bannk dengan predikat tidak baik untuk pertama kalinya menjadi $0.0 \%$ yang berarti tidak ada lagi bank umum yang tidak baik dalam pelaksanaan GCG.

\section{Hambatan hambatan yang} dihadapi dalam implementasi self assessment Good corporate governance bagi Bank Go Public

Terdapat hambatan hambatan di dalam implementasi GCG yaitu faktor internal dan faktor eksternal. Kendala Eksternal dalam penerapan

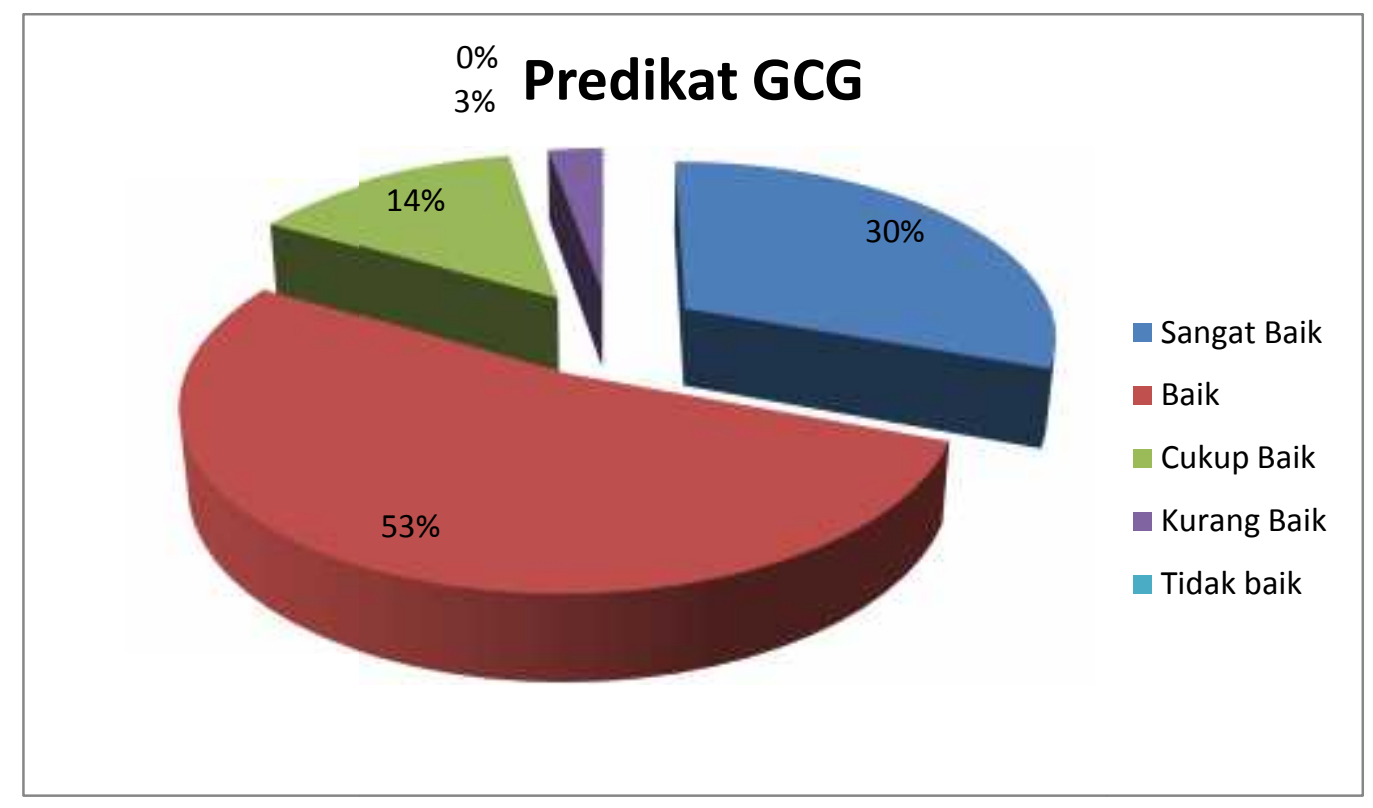

Dari 36 Bank yang sudah Go

GCG meliputi :

Public 11 Bank mendapatkan predikat sangat baik, sedangkan 19 1.Sistem hukum dan bank dengan predikat baik. Adapun penegakannya 
2.Good governance dan Standar professionalme

3.Sosial value system.

Kendala Internal dalam penerapan

GCG :

1.Komitemen organ perusahaan dan Budaya perusahaan

2.Pemahaman SDM tentang GCG

3.Kurang efektifitas sistem pengendialian internal
1. Regulasi yang mendukung implementasi GCG dan diserai Law Enforcement.

2. Depolitisasi perusahaan dan mendorong agar lebih independen dan

3. Perbaikan good corporate governance secara simultan.

Upaya internal dalam penerapan GCG meliputi:

1. Restrurturisasi internal dengan membenahan budaya kerja dan perbaikan regulasi

2. Komitemen kuat dari seluruh organ perusahaan dan panutan dan teladan dari top manaemmen

3. Implementasi secara simultan dan konsisten

\section{Upaya upaya yang dilakukan} untuk menyatasi hambatan dalam pelaksaaan GCG di bank public

Untuk antisipasi supaya di dalam pelaksanaan GCG tidak terjadi hambatan maka harus memperhatikan dengann upaya eksternal dan internal.

Upaya eksternal dalam penerapan GCG bagi bank go public adalah meliputi :

\section{PENUTUP}

\section{Simpulan}

Bertitik tolak dari uraian di atas,dapatlah ditarik tiga simpulan sebagai berikut:pertama,Secara numum penerpaan GCG sudah sesaui dengan prinsip prinsip GCG yang ada yaitu : (1) Transporatasi (2) akuntabilitas (3) bertanggungjawab (4) kemandirian dan (5) kewajaran. Dari 36 Bank yang sudah Go Public 11 Bank mendapatkan predikat 
sangat baik, sedangkan 19 bank dengan predikat baik. Adapun bank bank yang masuh perlu perbaikan yaitu 5 bank mendapatkan predikat cukup bank dan 1 bank kurang baik; Kedua,Terdapat hambatan hambatan di dalam implementasi GCG yaitu faktor internal dan faktor eksternal. Kendala Eksternal dalam penerapan GCG meliputi (1) Sistem hukum dan penegakannya (2) Good governance (3) Standar professionalme (4) Sosial value system. Kendala Internal dalam penerapan GCG (1) Komitemen organ perusahaan (2) Budaya perusahaan (3) Pemahaman SDM tentang GCG (4) Kurang panutan/teladan darii pimpinan (5) Efektifitas sistem pengendialian internal.

Ketiga,Untuk antisipasi supaya di dalam pelaksanaan GCG tidak terjadi hambatan maka harus memperhatikan dengann upaya eksternal dan internal. Upaya eksternal dalam penerapan GCG bagi bank go public adalah meliputi (1) Regulasi yang mendukung implementasi GCG dan diserai Law Enforcement. (2) Depolitisasi perusahaan dan mendorong agar lebih independen dan (3) Perbaikan good corporate governance secara simultan. Upaya internal dalam penerapan GCG meliputi (1) Restrurturisasi internal dengan membenahan budaya kerja dan perbaikan regulasi (2) Komitemen kuat dari seluruh organ perusahaan (3) Panutan dan teladan dari top manaemmen (4) Komite dari seluruh pegawai (5) Implementasi secara simultan dan konsisten

\section{Saran}

Dari kesimpulan tersebut, dapat dikemukakan tiga saran sebagai berikut: 1). Penelitian lebih lamjut perlu dikembangkan bukan hanya pada bank publik yang terdarftar di bursa efek namun juga bank yang belum masuk ke Bursa, seperti bank swasta, bank syariah dan Bank Perkreditan Rakyat; 2). Mendorong bank yang belum go public untuk segara melaksanaan go public agar pengawasan publik terhadap bank semakin baik; 3). Revisi Undang Undang Perbankan dan memasukan ketentuan tentang self assessment good corporate governance sebagai dasar hukum bukan hanya dari Peraturan Bank Indonesia namun juga dimasukan kedalam Undang Undang tentang Perbankan. 
DAFTAR PUSTAKA

Abdul Kadir Muhammad, Hukum dan Penelitian Hukum, Bandung, PT Citra Aditya

Bakti, 2004

Bank Indonesia, 2008, Laporan Pengawasan Perbankan Jakarta

Bank Indonesia, 2009,Laporan Pengawasan Perbankan Jakarta

Bank Indonesia, 2006, Laporan Pengawasan Perbankan, Jakarta

Bank Indonesia, 2007,Laporan Pengawasan Perbankan,

Jakarta

Basel Committee on Bankin Supervision, Enhancing Corporate Governance for Banking Organizations: Bassel: Bank for International Settlement Press, 2006

Binhadi, 2007, Elaboration of Indonesian Code of Corporate Governance, Sustaining Value though GCG based on business practices" National
Committee on Governance, Nusa Dua, Bali

Ferry Idroes, 2008, Manajemen Risiko Perbankan, Pemahaman Pendekatan 3 Pilar Kesepakatan Basel II, Terkait Implementasi Regulasi dan Pelaksanaannya di Indonesia, Rajawali Press G. Supriyitno, dkk, 2004, Komiten Menegakkan Good Coprate governance, the Indonesian Institute for Corporate Governance, Jakarta

Iqbal dan Mirakhor, 2008, Pengantar Keuangan Islam: Teori dan Praktik. Diterjemahkan oleh AK Anwar . Kencana , Jakarta Mal An Abdullah, 2010, Corporate Governance Perbankan Syariah di Indonesia, Ar Ruzz Media, Yogyakarta

Rianto Nugroho, 2003, Reinventing Pembangunan: Menata Ulang Pebangunan untuk Membangun Indonesia Baru dengan Keunggulan Blobal, PT Elek Media Komputindo, Jakarta 
Siddharta Uta,ma dan Cynthia

Afriani, 2003, Praktik

Coporate Goverannce dan

Penciptaan Nilai

Perusahaan: Studi Empiris

di BEJ, Usahawan No 08

TH XXXIV/Agustus 2005,

Jakarta, hlm 3 Tjager dkk,

Coporate Governance

Tantangan dan kesempatan

bagi komunitas bisnis

Indonesia, PT Prenhalindo,

Jakarta

Soerjono Soekantoi \& Sri

Mamudji, 2004,Penelitian

Hukum Normatif Suatu

Tinjauan Singkat,

PT.RajaGrafindo Persada

Jakarta

Sutojo dan Aldridge, 2005, Good

Corporate Governance: Tata

Kelola Perusahaan yang

sehat, Jakarta: Dharma

Mulia Pustaka

Syakhroza, 2005, Corporate

Governance: Sejarah dan

Perkembangan. Teori,

Model dan System

Governance serta

aplikasinya pada perusahaan

BUMN. Jakarta: lembaga

penerbit FEIU, Jakarta 